\title{
Seismicity of the northern part of the Itoigawa-Shizuoka Tectonic Line
}

\author{
Shin'ichi Sakai \\ Earthquake Research Institute, University of Tokyo, 1-1-1 Yayoi, Bunkyo-ku, Tokyo-to 113-0032, Japan
}

(Received July 2, 2004; Revised December 14, 2004; Accepted December 24, 2004)

\begin{abstract}
The relationship between recent seismicity and the active fault system was investigated using the precise hypocentral distribution by taking into consideration the heterogeneity of the velocity structure around the northern part of the Itoigawa-Shizuoka Tectonic Line (ISTL), the western boundary of the northern Fossa Magna basin. Since a velocity structure suitable for the ISTL is necessary for precise hypocentral determination, deep seismic reflection and refraction profiling were undertaken in 2002 across the northern part of the ISTL and a reliable velocity model was obtained. The hypocenters were located using the station corrections derived from the velocity model. The obtained hypocenters were found to be distributed in a straight line in an almost north-tosouth direction. The hypocenters, whose lower limit was approximately $15 \mathrm{~km}$, were distributed around a vertical plane. The focal mechanism solutions were primarily strike-slip and the direction of their P-axis was NW-SE to WNW-ESE. The fault planes expected from these mechanisms are consistent with the distribution of the hypocenters. However, they are not consistent with the thrust fault planes of previous large earthquakes, which were inferred from the near-surface feature of the active fault system. This suggests that the recent seismicity cannot be attributed to aftershocks of the previous large earthquakes and is not induced by the movement of the active thrust fault.
\end{abstract}

Key words: Itoigawa-Shizuoka Tectonic Line, seismicity, precise hypocenter.

\section{Introduction}

The northern part of the Itoigawa-Shizuoka Tectonic Line (ISTL) is the western boundary of the northern Fossa Magna basin and a geological boundary between the old pre-Tertiary basement and the relatively new Neogene sedimentary basin. The ISTL is an active fault system and is recognized as having one of the largest slip rates in the Japanese islands. The slip rate of the Gofukuji Fault, located in the central ISTL, is estimated to be approximately $8.0 \mathrm{~mm} / \mathrm{yr}$ based on geomorphological and geological studies (Okumura et al., 1994). Across the northern part of the ISTL, GPS measurements indicate horizontal crustal shortening (Sagiya et al., 2002). The present paper investigates the relationship between recent seismicity and the ISTL, which has a large lateral heterogeneity and a large slip rate. The precise hypocentral distribution obtained in consideration of the heterogeneity of the velocity structure may show the current situation of the active fault system and may predict the conditions for the next large earthquake.

\section{Seismic observation}

The High Sensitivity Seismograph Network (Hi-net) has been deployed by the National Research Institute for Earth Science and Disaster Prevention, and the waveform data are continuously recorded by the Japan Meteorological Agency (JMA). Although the detection capability and determination accuracy of an earthquake have been improved by the new system, hypocenter determination around the ISTL

Copy right(c) The Society of Geomagnetism and Earth, Planetary and Space Sciences (SGEPSS); The Seismological Society of Japan; The Volcanological Society of Japan; The Geodetic Society of Japan; The Japanese Society for Planetary Sciences; TERRAPUB remains difficult because the ISTL is a major geological boundary and there is a great difference between the velocity structures of the eastern and western sides (Sato et al., 2004). Consequently, errors in hypocentral determinations are large and the distribution of the hypocenters is extended in the vertical direction. A suitable velocity structure is essential to precisely determine the hypocenter in the large lateral heterogeneity. Deep seismic reflection and refraction profiling were undertaken in 2002 across the northern part of the ISTL (Imai et al., 2004; Takeda et al., 2004). In these studies, a suitable velocity structure was obtained and was used for the present hypocentral determination.

\section{Hypocenter Distribution}

Hypocenters were determined by the maximumlikelihood estimation technique described by Hirata and Matsu'ura (1987). Since the study area has large lateral heterogeneity, three different velocity models were used in the different regions (Fig. 2). The models were derived from previous refraction experiments (Imai et al., 2004; Takeda et al., 2004). Model number 1 has a thick low velocity layer and was adopted for the regions around the ISTL (1, 2, 6 and 8 in Fig. 1); model number 2 was adapted to the region south-east of the ISTL (9 in Fig. 1), which is covered with volcanic products; and model number 3 was adapted for the remaining regions (3, 4, 5 and 7 in Fig. 1).

Hypocenters were located initially using the above three velocity models and arrival times without station corrections. Differences between the observed and estimated travel times were calculated for each station (O-C times) and these were averaged only over the earthquakes that occurred within each of the nine regions shown in Fig. 1. Nine 

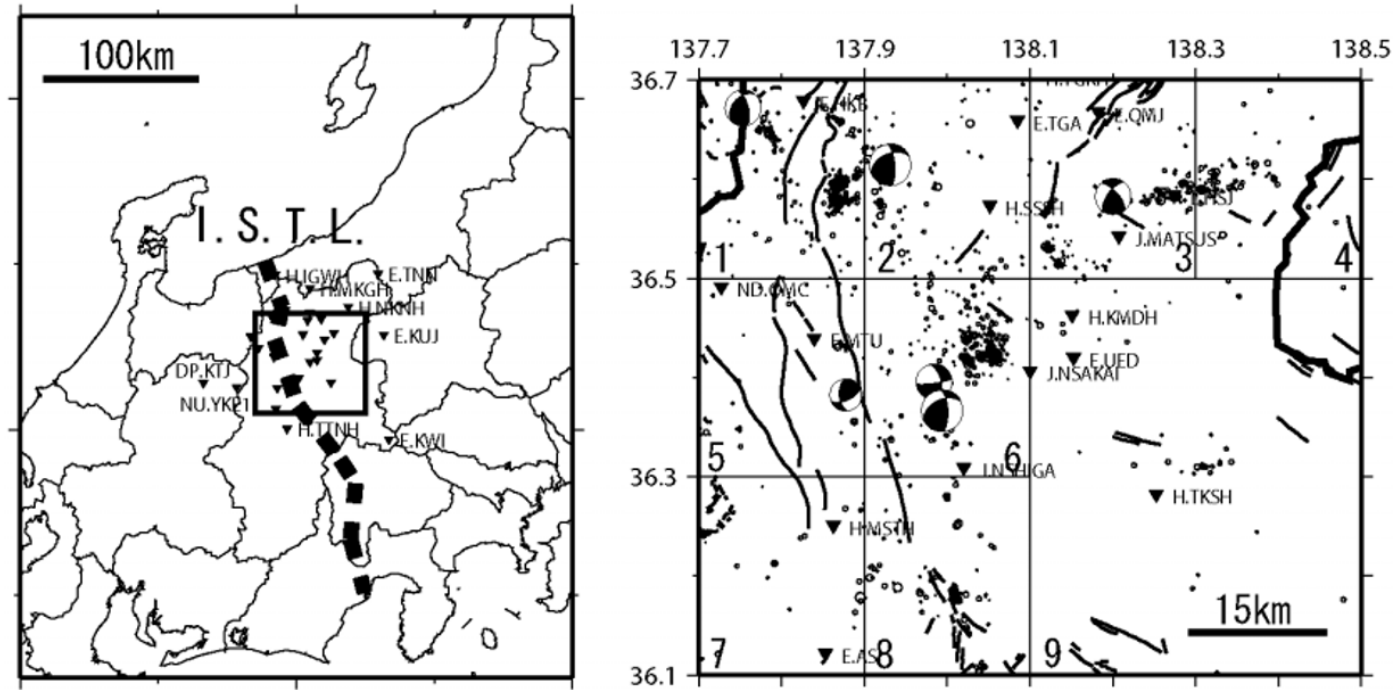

Fig. 1. A location map of the Itoigawa-Shizuoka Tectonic Line (ISTL) is shown in the figure on the left. The square indicates the present study area and the broken line indicates the ISTL. The inverted triangles indicate telemetered seismic stations. Focal mechanism solutions larger than M3.5 in this area are shown in the figure on the right by lower hemisphere projection. The major faults are indicated by a thin line. The hypocenters were determined using different station corrections for the nine regions.

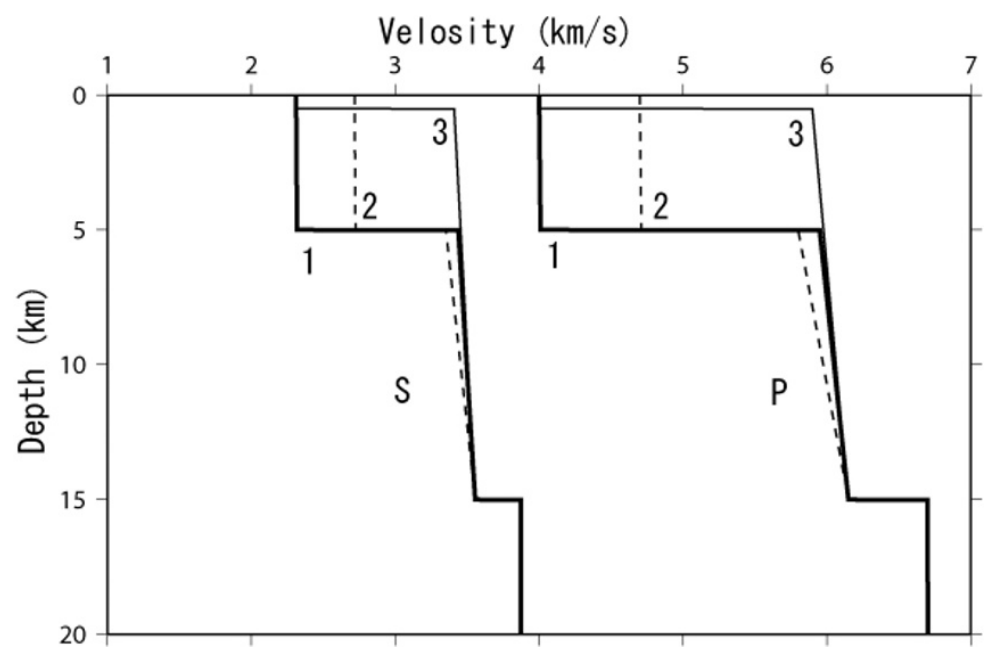

Fig. 2. P-wave and S-wave velocity structure models for hypocenter determination. These models were derived from previous refraction experiments (Imai et al., 2004; Takeda et al., 2004). Model numbers 1 (thick line), 2 (broken line) and 3 (thin line) were adapted for the regions around the ISTL (1, 2, 6 and 8 in Fig. 1), for the south-east region (9) and for the other regions (3, 4, 5 and 7), respectively.

averaged O-C-times were obtained for each station. Next, the hypocenters were located using the averaged $\mathrm{O}-\mathrm{C}$ times as station-correction values. A new set of averaged O-C times for each station was calculated from the results of the second location procedure. Finally, the new averaged O$\mathrm{C}$ times were added to the previous correction values, and the hypocenters were located again. This relocation process was repeated five times, at which point the final correction values for each station decreased by less than $0.01 \mathrm{~s}$; the obtained final O-C values for each station of the nine regions are listed in Table 1. At the end of this analysis, the averaged $\mathrm{O}-\mathrm{C}$ times of hypocenter determination decreased from $0.131 \mathrm{~s}$ to $0.054 \mathrm{~s}$ for P-wave arrival, and from 0.193 $\mathrm{s}$ to $0.100 \mathrm{~s}$ for $\mathrm{S}$-wave arrival (Table 1). The shape of the curve of frequency became sharp and the deviation is smaller (Fig. 3). Some 1829 hypocenters were selected with the criteria of small spatial errors of less than $1 \mathrm{~km}$ in the horizontal direction and less than $2 \mathrm{~km}$ in depth. The period of observation was from 1 January, 2001 to 31 December, 2003.

\section{Discussion}

The hypocenters around the northern part of the ISTL were distributed in a straight line in an almost north-tosouth direction (Fig. 4). The hypocenters were distributed around a vertical plane and their lower limit was approximately $15 \mathrm{~km}$. Although a similar distribution was obtained from the analysis using a uniform one-dimensional velocity structure, the distribution shown in Fig. 4 is clearer than that by the uniform velocity structure. The active fault system around the northern part of the ISTL has a strike in a north-to-south direction. Earthquakes have occurred only in the layer whose velocity is about $6.0 \mathrm{~km} / \mathrm{s}$ (Fig. 5). Many earthquakes have occurred in the upper crust of the eastern 
Table 1. The final station corrections of each station of the nine regions shown in Fig. 1. The upper and lower values for each station are the station corrections of the P-and S-waves, respectively. The numerals attached to the station corrections are the number of earthquakes used for the calculation of the station correction.

\begin{tabular}{|c|c|c|c|c|c|c|c|c|c|c|c|c|c|c|c|c|c|c|}
\hline \multirow[b]{2}{*}{ E.ASI } & \multicolumn{2}{|r|}{1} & \multicolumn{2}{|c|}{2} & \multicolumn{2}{|c|}{3} & \multicolumn{2}{|r|}{4} & \multicolumn{2}{|c|}{5} & \multicolumn{2}{|c|}{6} & \multicolumn{2}{|r|}{7} & \multicolumn{2}{|r|}{8} & \multicolumn{2}{|r|}{9} \\
\hline & 74 & 0.11 & 12 & 0.42 & 11 & 0.139 & 6 & -0.069 & 50 & 0.12 & 296 & 0.062 & 68 & 0.027 & 172 & -0.002 & 15 & -0.054 \\
\hline & 6 & -0.863 & 0 & & 2 & -0.243 & 3 & -0.702 & 31 & -0.186 & 64 & -0.767 & 59 & -0.513 & 170 & -0.408 & 8 & -0.68 \\
\hline \multirow[t]{2}{*}{ E.HKB } & 672 & 0.005 & 54 & -0.06 & 29 & 0.092 & 8 & 0.264 & 14 & -0.074 & 71 & 0.094 & 5 & -0.196 & 27 & 0.126 & 3 & 0.217 \\
\hline & 629 & -0.388 & 45 & -0.523 & 8 & 0.169 & 2 & -0.03 & 9 & -0.298 & 36 & -0.48 & 2 & -0.968 & 12 & -0.526 & 0 & \\
\hline \multirow[t]{2}{*}{ E.HSJ } & 518 & -0.318 & 74 & -0.233 & 258 & -0.019 & 101 & 0.056 & 22 & 0.041 & 446 & -0.092 & 24 & -0.203 & 105 & -0.254 & 52 & -0.005 \\
\hline & 201 & -0.959 & 63 & -0.914 & 249 & -0.052 & 98 & -0.273 & 3 & -0.259 & 352 & -0.763 & 0 & & 31 & -1.231 & 44 & -0.532 \\
\hline \multirow[t]{2}{*}{ E.KUJ } & 15 & 0.252 & 6 & 0.114 & 97 & 0.498 & 66 & 0.217 & 0 & & 39 & 0.361 & 0 & & 11 & 0.408 & 9 & 0.341 \\
\hline & 0 & & 0 & & 6 & 0.848 & 22 & 0.004 & 0 & & 0 & & 0 & & 0 & & 0 & \\
\hline E.KWI & 5 & -0.046 & 4 & -0.069 & 8 & -0.198 & 5 & -0.388 & 0 & & 47 & -0.352 & 4 & -0.041 & 62 & -0.128 & 21 & -0.195 \\
\hline & 0 & & 0 & & 0 & & 0 & & 0 & & 0 & & 0 & & 4 & -0.897 & 6 & -1.214 \\
\hline E.KYJ & 757 & 0.068 & 69 & -0.082 & 49 & -0.22 & 14 & -0.157 & 63 & 0.001 & 357 & -0.118 & 51 & -0.025 & 110 & -0.071 & 9 & -0.151 \\
\hline & 739 & -0.461 & 48 & -0.797 & 14 & -0.723 & 0 & & 58 & -0.133 & 148 & -0.98 & 37 & -0.847 & 33 & -0.874 & 3 & -0.986 \\
\hline E.MTU & 692 & 0.149 & 58 & 0.268 & 52 & 0.147 & 17 & 0.155 & 61 & 0.02 & 414 & 0.085 & 54 & 0.128 & 123 & 0.263 & 12 & 0.076 \\
\hline & 639 & -0.309 & 36 & -0.175 & 10 & 0.099 & 0 & & 41 & -0.014 & 283 & -0.388 & 32 & -0.317 & 55 & -0.086 & 3 & -0.311 \\
\hline E.OMJ & 300 & 0.522 & 33 & 0.47 & 201 & 0.035 & 58 & 0.187 & 0 & & 104 & 0.37 & 4 & 0.276 & 19 & 0.217 & 10 & 0.32 \\
\hline & 7 & 1.039 & 5 & 0.712 & 101 & 0.416 & 11 & 0.29 & 0 & & 11 & 0.441 & 0 & & 0 & & 2 & 0.469 \\
\hline ETGA & 549 & 0.333 & 75 & 0.198 & 207 & 0.126 & 74 & 0.345 & 17 & 0.901 & 193 & 0.466 & 7 & 0.666 & 20 & 0.413 & 15 & 0.311 \\
\hline & 76 & 0.291 & 41 & 0.071 & 61 & 0.446 & 19 & 0.278 & 2 & 1.899 & 9 & 0.519 & 0 & & 0 & & 0 & \\
\hline E.TNN & 9 & -0.004 & 3 & -0.168 & 15 & -0.012 & 28 & -0.312 & 0 & & 12 & 0.2 & 0 & & 2 & 0.438 & 0 & \\
\hline & 0 & & 0 & & 3 & -0.412 & 15 & -1.067 & 0 & & 0 & & 0 & & 0 & & 0 & \\
\hline E.UED & 508 & -0.065 & 80 & -0.031 & 238 & 0.01 & 97 & -0.049 & 40 & 0.158 & 486 & 0.068 & 45 & 0.061 & 165 & 0 & 53 & 0.09 \\
\hline & 198 & -0.753 & 62 & -0.609 & 197 & -0.04 & 72 & -0.634 & 22 & 0.028 & 486 & -0.445 & 19 & -0.672 & 93 & -0.576 & 55 & -0.321 \\
\hline DP.KTJ & 14 & 0.031 & 0 & & 2 & -0.159 & 0 & & 8 & 0.078 & 12 & -0.276 & 14 & -0.15 & 8 & -0.157 & 0 & \\
\hline & 0 & & 0 & & 0 & & 0 & & 3 & -0.248 & 0 & & 3 & -0.968 & 0 & & 0 & \\
\hline H.IGWH & 56 & -0.215 & 4 & -0.046 & 5 & -0.099 & 0 & & 0 & & 0 & & 0 & & 0 & & 0 & \\
\hline & 34 & -1.006 & 3 & -0.698 & 2 & -0.239 & 0 & & 0 & & 0 & & 0 & & 0 & & 0 & \\
\hline H.KMDH & 69 & -0.009 & 18 & -0.039 & 64 & 0.047 & 27 & 0.004 & 8 & 0.082 & 87 & 0.111 & 3 & -0.053 & 13 & -0.018 & 17 & 0.023 \\
\hline & 25 & -0.623 & 15 & -0.691 & 58 & 0.042 & 26 & -0.504 & 6 & 0.025 & 82 & -0.436 & 0 & & 3 & -0.666 & 17 & -0.52 \\
\hline H.MKGH & 37 & 0.079 & 7 & 0.117 & 12 & 0.162 & 2 & 0.188 & 0 & & 7 & 0.629 & 0 & & 0 & & 0 & \\
\hline & 16 & -0.378 & 2 & -0.314 & 3 & 0.418 & 2 & -0.119 & 0 & & 0 & & 0 & & 0 & & 0 & \\
\hline H.MSTH & 50 & 0.131 & 10 & 0.513 & 6 & 0.181 & 0 & & 14 & 0.055 & 99 & 0.1 & 28 & 0.059 & 114 & 0.0 & 12 & 0.0 \\
\hline & 26 & -0.504 & 3 & 0.118 & 0 & & 0 & & 11 & -0.003 & 50 & -0.562 & 28 & -0.395 & 97 & -0.362 & 5 & -0.614 \\
\hline H.NKNH & 33 & -0.187 & 5 & -0.114 & 54 & -0.189 & 45 & -0.255 & 0 & & 26 & -0.04 & 0 & & 0 & & 10 & -0.175 \\
\hline & 2 & -0.668 & 0 & & 39 & -0.491 & 39 & -0.931 & 0 & & 5 & -0.899 & 0 & & 0 & & 4 & -0.93 \\
\hline H.SSSH & 46 & 0.674 & 13 & 0.351 & 23 & 0.27 & 0 & & 2 & 0.855 & 18 & 0.478 & 0 & & 0 & & 3 & 0.351 \\
\hline & 21 & 0.90 & 7 & 0.291 & 8 & 0.63 & 0 & & 0 & & 6 & 0.51 & 0 & & 0 & & 0 & \\
\hline H.TGKH & 30 & 0.433 & 12 & 0.328 & 55 & 0.378 & 10 & 0.636 & 3 & 1.132 & 28 & 0.865 & 0 & & 0 & & 6 & 0.619 \\
\hline & 12 & 0.351 & 4 & 0.301 & 27 & 0.862 & 5 & 0.953 & 0 & & 0 & & 0 & & 0 & & 2 & 0.76 \\
\hline H.TKSH & 23 & -0.025 & 12 & 0.073 & 49 & 0.253 & 15 & 0.241 & 6 & 0.029 & 111 & 0.036 & 9 & -0.0 & 106 & 0.024 & 27 & 0.106 \\
\hline & 8 & -0.696 & 7 & -0.58 & 23 & 0.291 & 7 & -0.134 & 3 & -0.143 & 96 & -0.609 & 2 & -1.029 & 96 & -0.5 & 25 & -0.304 \\
\hline H.TTNH & 21 & 0.104 & 3 & 0.495 & 6 & -0.036 & 2 & -0.189 & 5 & 0.122 & 30 & 0.021 & 26 & 0.002 & 110 & 0.081 & 4 & -0.078 \\
\hline & 3 & -0.91 & 0 & & 0 & & 0 & & 3 & -0.198 & 8 & -0.797 & 11 & -0.778 & 100 & -0.4 & 0 & \\
\hline ND.OMC & 688 & -0.018 & 42 & -0.074 & 55 & -0.195 & 14 & -0.099 & 53 & -0.059 & 367 & -0.16 & 42 & -0.101 & 108 & -0.064 & 11 & -0.197 \\
\hline & 604 & -0.552 & 25 & -0.727 & 14 & -0.637 & 0 & & 38 & -0.117 & 211 & -0.939 & 26 & -0.783 & 17 & -0.792 & 4 & -0.981 \\
\hline NU.YKE1 & 42 & -0.006 & 9 & 0.124 & 3 & -0.223 & 4 & -0.258 & 45 & 0.05 & 80 & -0.156 & 60 & 0.033 & 86 & -0.139 & 0 & \\
\hline & 0 & & 0 & & 0 & & 0 & & 33 & -0.192 & 8 & -1.259 & 47 & -0.526 & 20 & -1.067 & 0 & \\
\hline J.MATSUS & 605 & -0.215 & 84 & -0.149 & 258 & -0.016 & 101 & -0.065 & 33 & 0.108 & 481 & -0.051 & 31 & -0.089 & 126 & -0.2 & 54 & -0.07 \\
\hline & 238 & -0.821 & 57 & -0.762 & 233 & -0.026 & 78 & -0.517 & 4 & -0.241 & 366 & -0.631 & 6 & -0.842 & 25 & -0.94 & 45 & -0.577 \\
\hline J.NSAKAI & 5 & 0.014 & 0 & & 6 & 0.104 & 8 & 0.111 & 6 & 0.043 & 29 & 0.069 & 0 & & 3 & 0.061 & 2 & -0.057 \\
\hline & 3 & -0.438 & 0 & & 5 & 0.162 & 2 & -0.718 & 5 & 0.217 & 28 & -0.499 & 0 & & 3 & -0.255 & 2 & -0.532 \\
\hline J.NSHIGA & 0 & & 0 & & 3 & -0.0 & 0 & & 4 & 0.199 & 66 & -0.034 & 2 & & 17 & 0.123 & 4 & -0.193 \\
\hline & 0 & & 0 & & 3 & -0.104 & 0 & & 4 & 0.439 & 57 & -0.58 & 2 & 0.204 & 15 & -0.089 & 3 & -0.693 \\
\hline
\end{tabular}

side of the ISTL.

The hypocenter distribution is not consistent with the fault plane of past thrust earthquakes, which is inferred from the near-surface feature of the active fault system. The active fault system is estimated by some geological studies and seismic experiments (Sato et al., 2004; Imai et al., 2004) to consist of east-dipping low-angle thrust faults with an azimuth of almost north-to-south in direction. The distribution of hypocenters around the northern part of the ISTL is a straight north-to-south and is located slightly eastward of the active fault system. Both distributions show essentially the same direction, suggesting the possibility that movement of the active fault induced the recent earthquake activity. However, the distribution of hypocenters is not east-dipping, but vertical. The focal mechanism solutions are mainly strike-slip and the direction of the P-axis is NWSE or WNW-ESE (Fig. 1). The fault planes expected from these mechanisms are consistent with the obtained distribution of hypocenters, and there is a clear distinction between the distribution of recent hypocenters and the geometry of the active fault system.

This distinction may originate in the difference in timescale. The present microearthquakes have been observed for only three years at most. The active fault system expresses the cumulative deformations of some million years. The recent earthquakes in this area reflect only the recent stress field and/or the easy-rupture zone. The fact that the distribution of the hypocenters forms a straight line 

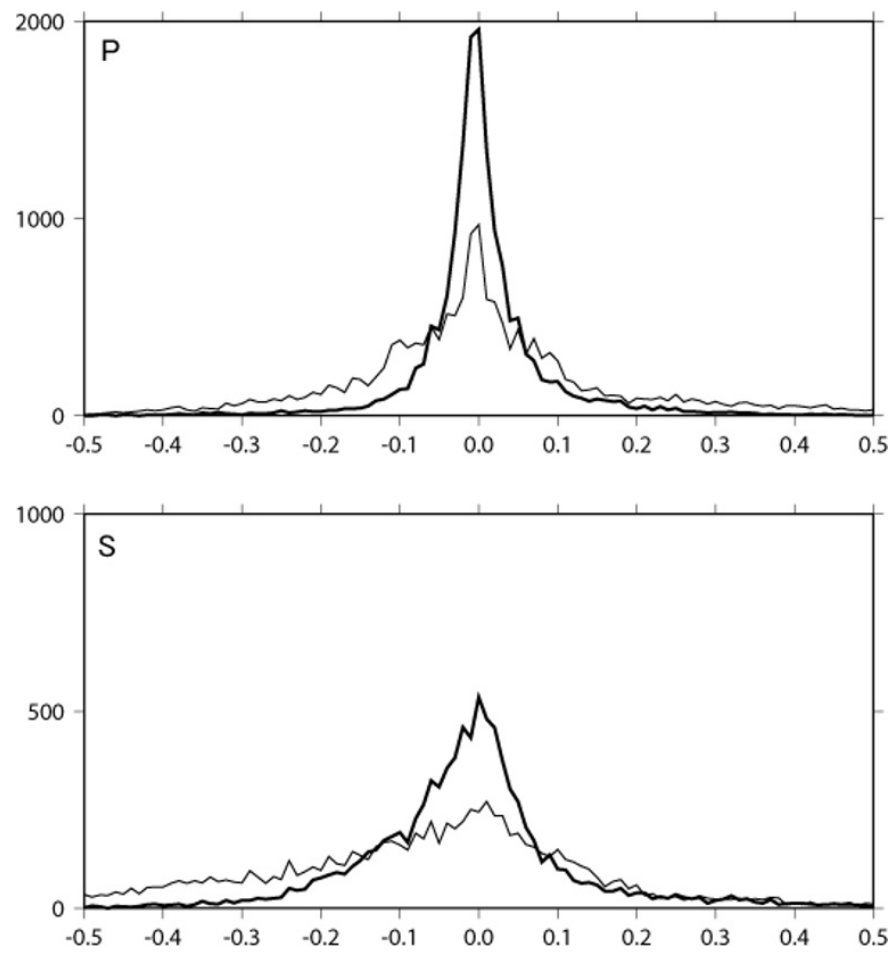

Fig. 3. The frequencies of the residuals for all stations are shown. Thin and thick lines represent the residuals of the initial and final frequencies, respectively. At the end of this analysis, the averaged residual of hypocenter determination decreased from 0.131 to $0.054 \mathrm{~s}$ for P-wave arrival and from 0.193 to $0.100 \mathrm{~s}$ for S-wave arrival. Note that the shape of the curve of frequency becomes sharp.

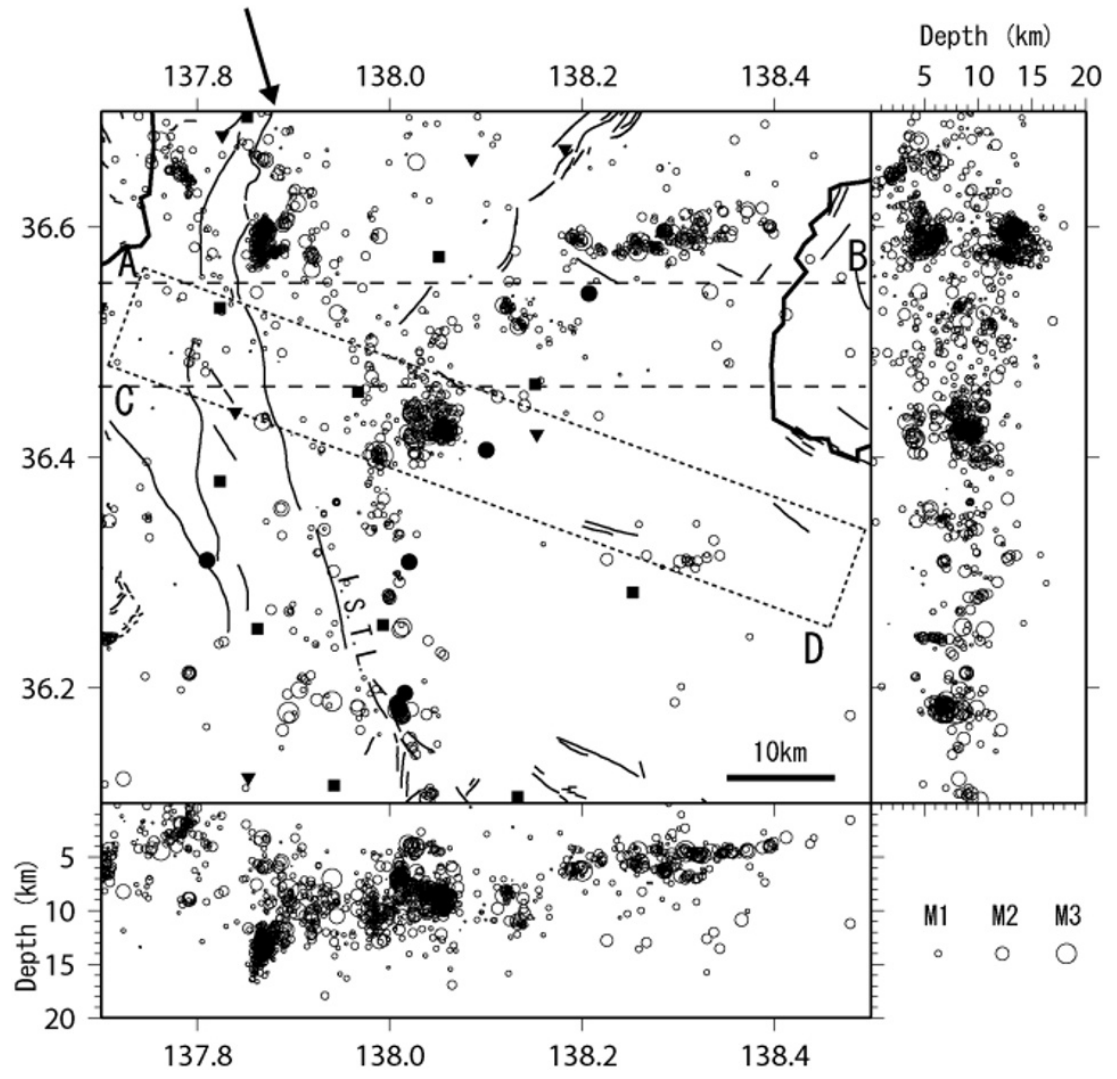

Fig. 4. Hypocenter distribution was obtained taking into consideration the heterogeneity of the velocity structure in the present study, which was carried out from 1 January, 2001 to 31 December, 2003. The solid circles, the solid inverted triangles and the solid squares indicate the positions of the seismic stations of the Japan Meteorological Agency, the Earthquake Research Institute and the National Research Institute for Earth Science and Disaster Prevention, respectively. The two squares with broken lines indicate the area of the profile in Fig. 5. The bottom area shows the E-W cross-section and the right shows the N-S cross-section. Hypocenters with an error of less than $1 \mathrm{~km}$ for the horizontal direction and less than 2 $\mathrm{km}$ in depth are plotted. In the horizontal section, the arrowed line indicates the distribution of hypocenters in a straight line in an approximately north-to-south direction. This distribution also exists in areas other than the ISTL. 


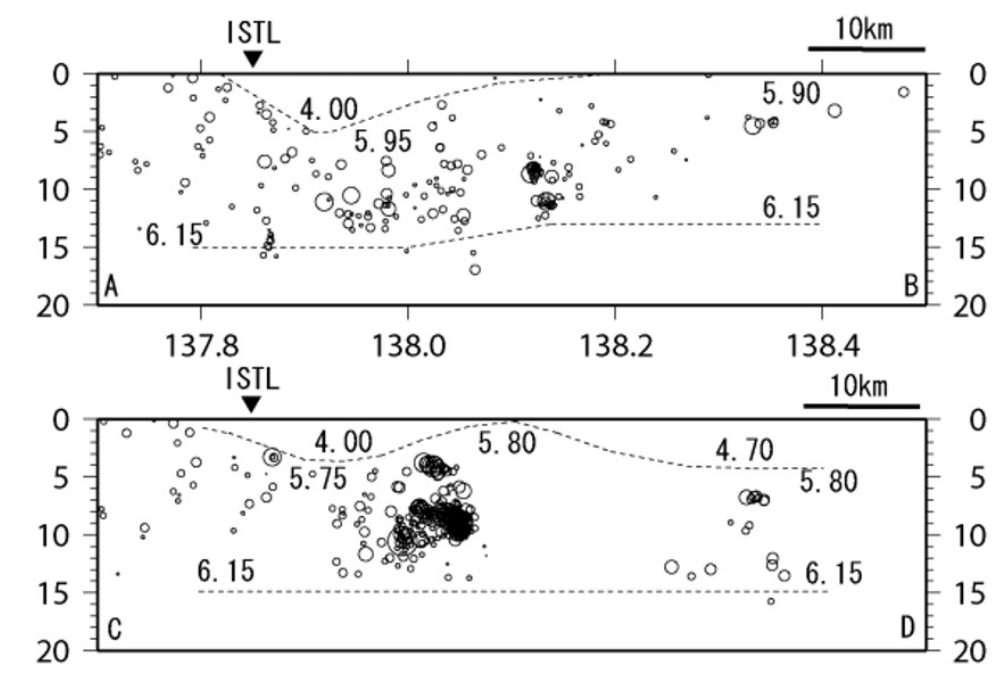

Fig. 5. Profile of the hypocenter distributions obtained taking into consideration the heterogeneity of the velocity structure. The top profile is the experiment line in the east-to-west direction (Takeda et al., 2004) and the bottom profile is the experiment line in the direction of WNW-ESE (Imai et al., 2004). The range of the profiles is shown by the two squares in Fig. 4. The simplified models of the velocity structures are indicated by the broken line and the value of the P-wave velocity. The solid triangle indicates the position of the ISTL. Earthquakes have occurred only in the layer whose P-wave velocity is about $6.0 \mathrm{~km} / \mathrm{s}$. Some earthquakes have occurred on the eastern side of the ISTL, and the distributions do not form a thrust fault plane of the previous large thrust earthquakes, which is expected from the near-surface feature of the active fault system.

suggests that recent stress is concentrated on this line and/or that the weak zone is locating along this line. It appears that the hypocenters do not express a fault plane which will be ruptured by a large earthquake in the near future or a fault plane which ruptured in the past.

Given that tectonic stress accumulation and crustal shortening always exist, the cumulative stress must necessarily be released from time to time. Usually, relatively small earthquakes with a strike-slip type occur in the upper crust in order to release the stress. However, it may be insufficient to release the stress only by these earthquakes. The remaining stress may thus be released by a large thrust earthquake, possibly when the rate of tectonic stress accumulation episodically increased and/or the stress exceeded the fault strength. This may be an explanation of the distinction between the distribution of recent earthquakes and the thrust faults identified around the northern part of the ISTL.

\section{Conclusion}

The relationship between recent seismicity and the ISTL, which has a large lateral heterogeneity, was investigated using the precise hypocentral distribution obtained taking into consideration the heterogeneity of the velocity structure. The precise hypocenters were determined by the velocity structure derived from the deep seismic reflection and refraction profiling which was carried out in 2002. The obtained hypocenters were found to be distributed in a straight north-to-south line. They were distributed around a vertical plane and had a lower limit of approximately $15 \mathrm{~km}$. The focal mechanisms were primarily strike-slip with a P-axis in the NW-SE or WNW-ESE direction. The fault planes expected from these mechanisms are consistent with the distribution of hypocenters, however, they are not consistent with the plane of the thrust fault of previous large earthquakes, which was inferred from the near-surface feature of the active fault system. This suggests that the recent seismicity is not related to aftershocks of previous large earthquakes or the displacement of the active thrust fault.

Acknowledgments. The author would like to offer special thanks to Mr. M. Kobayashi, Mr. S. Hashimoto and Mr. T. Haneda for their help with the temporary observations. He gratefully acknowledges helpful discussions with Dr. H. Sato, Dr. T. Iwasaki, Ms. T. Imai and Dr. T. Takeda. Comments by Dr. K. Katsumata and an anonymous reviewer helped him improve the manuscript. He also would like to offer special thanks to Dr. Y. Iio for his advice, his help, and encouragement. This study is a part of the research project on "Slip and Flow Processes in and below the Seismogenic Region".

\section{References}

Hirata, N. and M. Matsu'ura, Maximum-likelihood estimation of hypocenter with origin time eliminated using nonlinear inversion technique, Phys. Earth Planet. Inter., 47, 50-61, 1987.

Imai, T., T. Iwasaki, T. Takeda, T. Kawanaka and H. Sato, Detailed upper crustal structure across the Itoigawa-Shizuoka Tectonic Line from the 2002 seismic expedition, Proceedings of the 2nd International Symposium on Slip and Flow Process in and below the Seismogenic Region, 2004.

Okumura, K., K. Shimokawa, H. Yamazaki and E. Tsukuda, Recent surface faulting events along the middle section of the Itoigawa-Shizuoka Tectonic Line-trenching survey of the Gofukuji Fault near Matsumoto, central Japan—, Zisin, 46, 425-438, 1994 (in Japanese with English abstract).

Sagiya, T., T. Nishimura, Y. Iio and T. Tada, Crustal deformation around the northern and central Itoigawa-Shizuoka Tectonic Line, Earth Planets Space, 54, 1059-1063, 2002.

Sato, H., T. Iwasaki, S. Kawasaki, Y. Ikeda, N. Matsuta, T. Takeda, N. Hirata and T. Kawanaka, Formation and shortening deformation of a backarc rift basin revealed by deep seismic profiling across the ItoigawaShizuoka Tectonic Line active fault system, Central Japan, Tectonophysics, 2004 (in press).

Takeda, T., H. Sato, T. Iwasaki, N. Matsuta, S. Sakai, T. Iidaka and A. Kato, Crustal structure in the northern Fossa Magna region, central Japan, from refraction/wide-angle reflection data, Earth Planets Space, 56, this issue, 1295-1301, 2004.

S. Sakai (e-mail: coco@eri.u-tokyo.ac.jp) 